
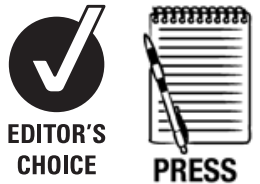

RELEASE

PAPER

\title{
Conscientious objection in medical students: a questionnaire survey
}

\author{
Sophie LM Strickland
}

- An additional appendix is published online only. To view this file please visit the journal online (http://jme.bmj.com/ content/38/1.toc)

King George Hospital, Barking, Havering and Redbridge University Hospitals, Essex, UK

Correspondence to

Sophie Strickland

sophiestrickland@doctors.net.uk

Received 26 January 2011

Revised 2 May 2011

Accepted 24 May 2011

Published Online First

18 July 2011

\section{ABSTRACT \\ Objective To explore attitudes towards conscientious objections among medical students in the UK.}

Methods Medical students at St George's University of London, Cardiff University, King's College London and Leeds University were emailed a link to an anonymous online questionnaire, hosted by an online survey company. The questionnaire contained nine questions. A total of 733 medical students responded.

Results Nearly half of the students in this survey stated that they believed in the right of doctors to conscientiously object to any procedure. Demand for the right to conscientiously object is greater in Muslim medical students when compared with other groups of religious medical students.

Discussion Abortion continues to be a contentious issue among medical students and this may contribute to the looming crisis in abortion services over the coming years. This project sheds some light on how future doctors view some of their ethical rights and obligations. Using empirical evidence, it reveals that conscientious objection is an issue in the UK medical student body today. These data could help anticipate problems that may arise when these medical students qualify and practise medicine in the community.

Conclusion Clearer guidance is needed for medical students about the issue of conscientious objection at medical school.

\section{INTRODUCTION}

The medical profession is fraught with ethical dilemmas. One such dilemma, much publicised following the publication of an article by Julian Savulescu, is the extent to which healthcare professionals can conscientiously object to treatment. ${ }^{1}$

In response to increasing numbers of enquiries from medical students and doctors regarding how to balance their own personal beliefs with their work, the General Medical Council (GMC) has published guidelines. These guidelines recognise the right to freedom of expression for medical students, but states that this "cannot compromise the fundamental purpose of the medical course: to train doctors who have the core knowledge, skills, attitudes and behaviour that are necessary at graduation.'

Despite the publicity, there are few empirical studies on the issue of conscientious objection in medicine. In 1993, Green surveyed UK obstetric consultants asking how late in a pregnancy they would be prepared to offer termination for anencephaly, spina bifida and Down's syndrome. ${ }^{3}$ In 2001, Savulescu surveyed a subgroup of clinical geneticists and obstetricians asking similar questions on willingness to perform termination of pregnancy. ${ }^{4}$ More recently (2007), Curlin et al undertook a cross-sectional study on the views of US physicians about a range of procedures, including abortion. ${ }^{5}$

The idea for the present study emerged from reading press reports that some medical students are refusing to learn about procedures by invoking conscientious objection. ${ }^{6}$ This paper presents the findings from a study on conscientious objection among medical students in the UK.

\section{METHODS \\ Participants}

Medical students at Cardiff University, King's College London, Leeds University and St George's University of London were contacted. All medical students at St Georges University of London were emailed. Only those students at the other institutions not involved in formal assessment at the time were invited to take part.

\section{Questionnaire}

Students were invited to complete an anonymous online questionnaire about conscientious objection hosted by the Survey Monkey website. ${ }^{7}$ Invitation emails were sent out on 5 May 2008, and the survey was closed on 24 June 2008.

In total, the questionnaire contained nine items, addressing student's opinions towards conscientious objection and attitudes towards a range of procedures. Questions addressed topical areas of healthcare predicted to conflict with their religious, moral or personal beliefs, including abortion, contraception, treatment of patients intoxicated with alcohol or recreational drugs plus intimate examination of a person of the opposite sex. Questions 6 and 7 were based on an existing questionnaire, and permission was gained from the original authors. ${ }^{5}$ Further questions collected information on type of medical degree (4- or 5-year $\mathrm{MBBS}$ ), gender, religion and ethnic origin. This questionnaire survey was reviewed by the Wandsworth Research Ethics Committee project and deemed not to need a full ethical review.

A pilot study on six second-year medical students at St Georges, University of London was conducted. The students were asked to complete the questionnaire and provide feedback on the structure and nature of questions. The final version of the questionnaire is given in online appendix 1 .

\section{Statistical analysis}

The results of each questionnaire were compiled by Survey Monkey, an online survey program, and 
the total responses to each question were compiled for analysis.

Results were analysed using Excel (Microsoft 2003) and are presented as frequencies and percentages.

\section{RESULTS}

\section{Demographics}

A large sample size of students completed the questionnaire. Of a total of 1437 medical students invited to take part, 733 responded, giving a response rate of $51 \%$.

Of those who responded, $265(36.0 \%)$ indicated their gender to be male and 468 (64.0\%) female, with no missing responses.

Six hundred and nineteen (77.3\%) studied 5-year MBBS/ $\mathrm{MBChB} / \mathrm{MBBCh}$ medicine and 113 (15.4\%) 4-year MBBS medicine.

Two hundred and fourteen $(29.3 \%)$ stated they had no religion, 87 (11.9\%) were atheist, 39 (5.3\%) were Hindu, nine $(1.2 \%)$ were Sikh, 12 (1.6\%) were Buddhist, 65 (8.9\%) were Muslim, 83 (11.4\%) were Roman Catholic, 126 (17.2\%) were Protestant, 11 $(1.5 \%)$ were Jewish, two (0.3\%) were Eastern Orthodox, and 83 $(11.4 \%)$ classified themselves as 'other'.

\section{Attitudes to conscientious objection}

In response to question 5 'Do you think that doctors should be entitled to object to any procedure for which they have a moral, cultural or religious disagreement?', a total of 327 (45.2\%) respondents agreed with the statement, 294 (40.6\%) students disagreed, while 103 (14.2\%) were unsure.

Responses to this question are tabulated against the respondents' religion (table 1). Attitudes as to whether doctors have a right to conscientious objection varied between the reported religions. With the exclusion of the Muslim, Eastern Orthodox and Sikh students, there is some similarity between the other religious groups, with $34-55 \%$ agreeing that doctors have a right to object to any procedure. Over three-quarters of Muslim students felt that doctors had a right to object to any procedure based on their morals, cultural or religious beliefs. The Eastern Orthodox and Sikh students have been excluded because there are too few to be representative.

\section{Conscientious objection in specific medical practice}

In question 6, students were asked if they would have an objection to performing 11 medical practices. The results are presented in table 2. 'I have no objection' represented $84.5 \%$ of all responses.

Table 1 Frequencies of responses, cross-tabulated by religion, to the question 'do you think that doctors should be entitled to object to any procedure for which they have a moral, cultural or religious disagreement?'

\begin{tabular}{lrrrr}
\hline Religion & \multicolumn{1}{l}{ Yes } & \multicolumn{1}{c}{ No } & \multicolumn{1}{c}{ Unsure } & Total \\
\hline Muslim & $48(76.2 \%)$ & $8(12.7 \%)$ & $7(11.1 \%)$ & 63 \\
Jewish & $6(54.5 \%)$ & $5(45.5 \%)$ & 0 & 11 \\
Other & $44(53.0 \%)$ & $30(36.1 \%)$ & $9(10.8 \%)$ & 83 \\
Protestant & $64(51.2 \%)$ & $38(30.4 \%)$ & $23(18.4 \%)$ & 125 \\
Roman Catholic & $38(46.3 \%)$ & $31(37.8 \%)$ & $13(15.9 \%)$ & 82 \\
Buddhist & $5(41.7 \%)$ & $6(50.0 \%)$ & $1(8.3 \%)$ & 12 \\
None or atheist & $106(35.5 \%)$ & $152(50.8 \%)$ & $41(13.7 \%)$ & 299 \\
Hindu & $13(34.2 \%)$ & $20(52.6 \%)$ & $5(13.2 \%)$ & 38 \\
Sikh & $1(14.3 \%)$ & $3(42.9 \%)$ & $3(42.9 \%)$ & 7 \\
Eastern Orthodox & 0 & $1(50.0 \%)$ & $1(50.0 \%)$ & 2 \\
\hline
\end{tabular}

Values are number (\%). The percentages are those within the religion.
The total number of objections raised across the 11 practices did not differ greatly between genders: $83.8 \%$ of female students and $85.6 \%$ of male students stated 'I have no objection' to the 11 medical practices; male students stated more religious objections $(21.5 \%)$ than female students (18.9\%).

Overall, $92.6 \%$ of students from the 4-year MBBS medicine course noted 'I have no objection' to the 11 procedures, and $83.2 \%$ of students from the 5-year $\mathrm{MBBS} / \mathrm{MBChB} / \mathrm{MBBCh}$ medicine courses noted 'I have no objection'. The 5-year students reported more religious objection (20.9\%) than the 4-year students (3.3\%).

Respondents were asked to note if their objections to the above 11 medical practices were for religious reasons, non-religious reasons or both religious and non-religious reasons. Of all the objections raised in the study, $19.7 \%$ were for religious reasons, $44.1 \%$ were for non-religious reasons, and $36.2 \%$ were for both religious reasons and non-religious reasons. Muslim students were more likely to report religious objections $(28.4 \%)$, followed by Protestant students $(27.0 \%)$ and then Roman Catholic students (23.01\%). Jewish students were the least likely to report religious objections (15.8\%). The proportion of nonreligious objections ranged from $96.7 \%$ in atheist students to $21.0 \%$ in Protestant students. The Sikh and Eastern Orthodox students have again been excluded because of their low numbers.

The proportion of students from each religious group stating objection to all of the medical practices outlined in question 6 ranged from $6.0 \%$ in atheist students to $30.0 \%$ in Muslim students.

When all of the objections to each of the 11 medical practices were analysed according to religion, the proportion of responses recording objection were greatest among Muslim students in all 11 procedures.

\section{DISCUSSION}

\section{Conscientious objection in medicine}

This survey revealed that nearly half of the students in this survey believed in the right of doctors to conscientiously object to any procedure. Once qualified as doctors, if all these respondents acted on their conscience and refused to perform certain procedures, it may become impossible for conscientious objectors to be accommodated in medicine.

However, there are subtle variations in the answers given in the questionnaire. Although $45.2 \%$ of respondents agreed that doctors can object to any procedure, this did not appear to be supported by the results in table 2 . It could be that, when asked if they thought that doctors should be able to object to any procedure, the students thought of more controversial procedures. On the other hand, the difference between the results could be because, although nearly half of the students believe in the general right for doctors to claim conscientious objection in medicine, they personally would not uphold this right in the procedures listed in table 2 .

Some conscientious objectors are accepted in the medical profession in the UK, and the GMC has issued clear guidelines about what doctors should do when they object to a procedure, stating that, if a medical practice conflicts with a doctor's religious or moral beliefs, then the doctor must explain this to the patient and refer the patient on. ${ }^{8}$

\section{Conscientious objection and religion}

This survey found that a greater percentage of the objections in the survey were for non-religious reasons than religious ones. The factors behind the non-religious objections were not specifically explored. It is sometimes easier to understand an objection based on religious teachings, rather than on an individual's personal 
Table 2 Students reporting an objection (religious, non-religious or both) to a total of 11 procedures

\begin{tabular}{|c|c|c|c|c|}
\hline Procedure & $\begin{array}{l}\text { Students reporting } \\
\text { objection to } \\
\text { procedure (\%) }\end{array}$ & $\begin{array}{l}\text { Students who } \\
\text { would not perform } \\
\text { procedure }(\%)\end{array}$ & $\begin{array}{l}\text { Muslim students } \\
\text { reporting objection } \\
\text { to procedure (\%) }\end{array}$ & $\begin{array}{l}\text { Muslim students who } \\
\text { would not perform } \\
\text { procedure (\%) }\end{array}$ \\
\hline Abortion for congenital abnormalities before 24 weeks & $22.2(n=160)$ & $15.8(n=114)$ & $49.2(n=30)$ & $32.8(n=20)$ \\
\hline Abortion for failed contraception before 24 weeks & $31.9(n=230)$ & $23.5(n=170)$ & $73.0(n=46)$ & $60.3(n=38)$ \\
\hline Abortion for a raped minor before 24 weeks & $13.1(n=94)$ & $10.5(n=75)$ & $16.4(n=10)$ & $11.5(n=7)$ \\
\hline Abortion for a raped minor after 24 weeks & $31.2(n=224)$ & $19.8(n=142)$ & $37.7(n=23)$ & $26.2(n=16)$ \\
\hline Examining or treating a patient intoxicated with alcohol & $8.5(n=62)$ & $1.2(n=9)$ & $17.2(n=11)$ & $1.6(n=1)$ \\
\hline Learning about the clinical impact of alcohol at medical school & $0.5(n=4)$ & $0.0(n=0)$ & $1.6(n=1)$ & $0.0(n=0)$ \\
\hline Examining or treating a patient intoxicated with recreational drugs & $9.2(n=67)$ & $1.6(n=12)$ & $18.5(n=12)$ & $1.5(n=1)$ \\
\hline Intimately examining a person of the opposite sex & $5.4(n=39)$ & $1.1(n=8)$ & $36.0(n=23)$ & $7.8(n=5)$ \\
\hline
\end{tabular}

Press attention has recently been focused on the issue of conscientious objection within Muslim medical students, ${ }^{6}$ and therefore the results of the Muslim students in the study are shown separately.

moral framework, but non-religious beliefs can be just as firmly held and as central to a person's life. It is perhaps too easy to equate conscientious objection with religious belief.

\section{Conscientious objection and abortion}

Abortion is probably the most highly debated issue in conscientious objection. The survey revealed that almost a third of students would not perform an abortion for a congenitally malformed fetus after 24 weeks, a quarter would not perform abortion for failed contraception before 24 weeks, and a fifth would not perform abortion on a minor who was the victim of rape. Interestingly, not all students in the survey who objected to the idea of performing an abortion would necessarily conscientiously object to performing it in practice (see table 2). However, if these students are prepared to perform a procedure despite their objection to it, it could be argued that they are compromising their own moral integrity and that they may experience some moral distress. It would be valuable to find out why they would still perform a procedure in the belief that it is morally wrong. Do they feel coerced into the perceived wrongdoing?

In light of increasing demand for abortions, these results may have implications for women's access to abortion services in the future. The Department of Health has issued statistics showing that, although there are an increasing number of abortions taking place in the UK, fewer doctors are willing to perform them. ${ }^{9}$ The Royal College of Obstetricians and Gynaecologists has issued a statement recognising the growing problem of its doctors refusing to train in abortion. It stated that it is 'aware of the slow but growing problem of trainees opting out of training in the termination of pregnancy and is therefore concerned about the abortion service of the future... The RCOG recognises that it is an important right for any doctor to object to performing abortion. The future of the sexual healthcare services requires careful workforce planning in order for abortion services to be available to the women who need it most. ${ }^{10}$

Furthermore, there are fewer students opting for a career in obstetrics and gynaecology, which could further complicate the problem. ${ }^{11}$ In 1995, it was the main career choice of 26 out of 545 UK graduates, in 1998 this was 16 out of 509, and by 2002 only six out of 487 . The RCOG has recognised the downturn in recruitment to the specialty in recent years and has stated that 'unless recruitment improves there will be insufficient obstetricians to deliver the NHS service'. ${ }^{12}$

\section{Conscientious objection at medical school}

While it is considered acceptable for doctors to object to medical procedures on moral or religious grounds, medical students are prohibited from doing the same. The GMC acknowledges that every medical student has 'a right to freedom of expression', but it also states that this 'cannot compromise the fundamental purpose of the medical course: to train doctors who have the core knowledge, skills, attitudes and behaviour that are necessary at graduation'. ${ }^{2}$

There have been reports that Muslim medical students are refusing to attend lectures on alcohol-related diseases, answer exam questions on alcohol-related issues, and treat patients of the opposite sex. ${ }^{6}$ The Sunday Times stated that a male Muslim medical student failed his final exams after refusing to carry out a basic examination of a female patient. ${ }^{6}$ No Muslim student in this study noted a conscientious objection to learning about the clinical aspects of alcohol. However, we found that $76.2 \%$ of the Muslim students in the study stated that doctors should be able to object to any procedure. This represented the largest proportion of any single religious group within the survey claiming the need for indiscriminate objection. Furthermore, a greater proportion of Muslim students reported an objection to procedures across all questions in table 2 when compared with all students in the study. The views of large numbers of Muslim students are contrary to GMC guidelines, and thus the medical profession needs to think about how it will deal with the conflict.

The 2-year Foundation Programme in the UK involves an array of clinical experiences in which all graduates must be able to treat a range of unselected and acutely ill patients. The GMC believes that, in such an environment, it would simply not be possible to accommodate personal and religious preferences. ${ }^{2}$ It specifically states that a foundation level doctor cannot practise while refusing to examine patients on grounds of gender or those patients whose illness can be attributed to their lifestyle. ${ }^{2}$ The foundation level doctor is often the first doctor seeing acute patients and any delay in assessment or treatment may lead to unnecessary harm to the patient. The current job allocation system, which equates to a lottery, may not give conscientiously objecting doctors the ability to avoid jobs in which they might encounter roles that they object to.

\section{CONCLUSIONS}

This project sheds some light on how future doctors view some of their ethical rights and obligations. Using empirical evidence, it reveals that conscientious objection is an issue in the UK medical student body today, particularly among Muslim medical students but also students from other faiths. These data could help anticipate problems that may arise when these medical students qualify and practise medicine in the community. 
This project also raises the question of whether medical students have a right to act according to their consciences while at medical school, as opposed to merely holding conscientious objections. The GMC does not believe that this right applies in all situations. This study has shown that approximately $40 \%$ of the medical students surveyed believe there are limits to conscientious objection. The normative questions remain, however: should there be such limits? If so, what should these be and who should decide?

\section{Competing interests None.}

Ethics approval This study was conducted with the approval of the Wandsworth Research Ethics Committee, London.

Provenance and peer review Not commissioned; externally peer reviewed.

\section{REFERENCES}

1. Savulescu J. Conscientious objection in medicine. BMJ 2006;332:294-7.

2. GMC. Education Committee Position Statement: Core Educational Outcomes. http:// www.gmc-uk.org/Core_Education_Outcomes_1.0.pdf_25396917.pdf laccessed 6 Jan 2011).
3. Green J. Ethics and late TOP. Lancet 1993:342:1179

4. Savulescu J. Is current practice around late termination of pregnancy eugenic and discriminatory? Maternal interests and abortion. J Med Ethics 2001:27:165-71.

5. Curlin FA, Lawrence RE, Chin MH, et al. Religion, conscience, and controversial practices. N Engl J Med 2007;356:593-600.

6. Foggo D. Taher A. Muslim medical students get picky. The Sunday Times 2007. http://www.timesonline.co.uk/tol/news/uk/health/article2603966.ece laccessed 6 Jan 2011).

7. Survey Monkey. http://www.surveymonkey.com (accessed 6 Jan 2011)

8. GMC. Good Medical Practice. http://www.gmc-uk.org/guidance/good_medical_ practice.asp (accessed 22 Jun 2011).

9. Department of Health. Abortion Statistics, England and Wales: 2007. http://www. dh.gov.uk/en/Publicationsandstatistics/Publications/PublicationsStatistics/DH 085508 (accessed 6 Jan 2011).

10. Royal College of Obstetricians and Gynaecologists. RCOG Statement on Article 'Abortion Crisis as Doctors Refuse to Perform Surgery'. http://www.rcog.org.uk/what we-do/campaigning-and-opinions/statement/rcog-statement-article-abortion-crisisdoctors-refuse- (accessed 6 Jan 2011)

11. Laurance J. Abortion crisis as doctors refuse to perform surgery. The Independent 2007. http://www.independent.co.uk/life-style/health-and-families/health-news/ abortion-crisis-as-doctors-refuse-to-perform-surgery-444909.html (accessed 6 Jan 2011).

12. Royal College of Obstetricians and Gynaecologists. Who Will Deliver Our Babies? http://www.rcog.org.uk/news/who-will-deliver-our-babies laccessed 6 Jan 2011).

Advancing Postgraduates. Enhancing Healthcare.

The Postgraduate Medical Journal is dedicated to advancing the understanding of postgraduate medical education and training

- Acquire the necessary skills to deliver the highest possible standards of patient care

- Develop suitable training programmes for your trainees

- Maintain high standards after training ends

Published on behalf of the fellowship for Postgraduate Medicine

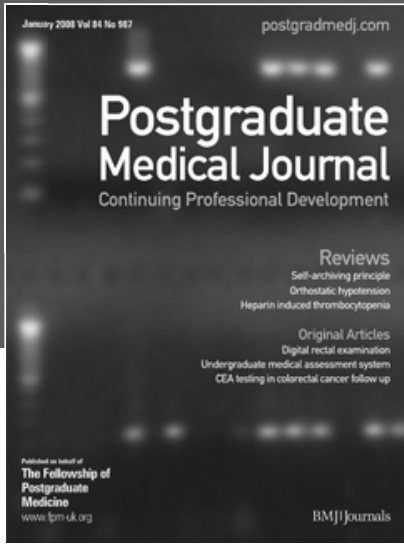

FOR MORE DETAILS OR TO SUBSCRIBE,

VISIT THE WEBSITE TODAY

BMJIJournals

postgradmedj.com

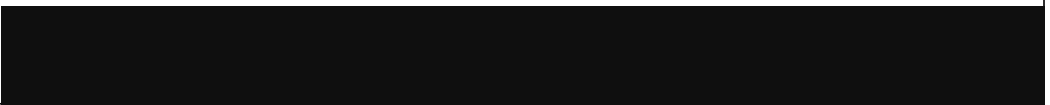

